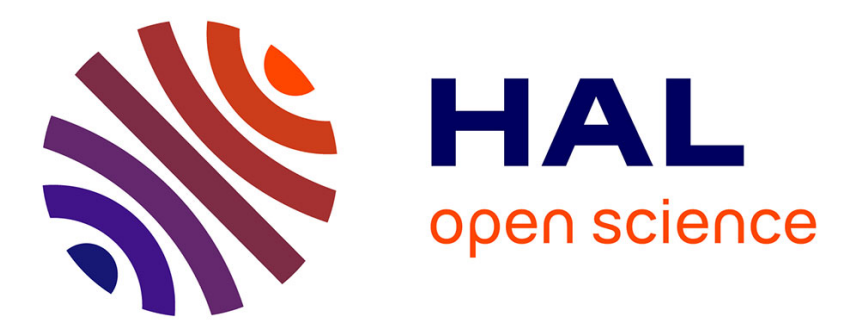

\title{
Oblique projection pre-processing and TLS application for diagnosing rotor bar defects by improving power spectrum estimation
}

Guillaume Bouleux

\section{- To cite this version:}

Guillaume Bouleux. Oblique projection pre-processing and TLS application for diagnosing rotor bar defects by improving power spectrum estimation. Mechanical Systems and Signal Processing, 2013, 41, pp.301 - 312. 10.1016/j.ymssp.2013.06.018 . hal-01508672

\section{HAL Id: hal-01508672 \\ https://hal.science/hal-01508672}

Submitted on 14 Apr 2017

HAL is a multi-disciplinary open access archive for the deposit and dissemination of scientific research documents, whether they are published or not. The documents may come from teaching and research institutions in France or abroad, or from public or private research centers.
L'archive ouverte pluridisciplinaire HAL, est destinée au dépôt et à la diffusion de documents scientifiques de niveau recherche, publiés ou non, émanant des établissements d'enseignement et de recherche français ou étrangers, des laboratoires publics ou privés.

\section{(ㄷ)(1) $\$$}

Distributed under a Creative Commons Attribution - NonCommerciall 4.0 International 


\title{
Oblique Projection pre-Processing and TLS application for diagnosing rotor bar defects by improving power spectrum estimation
}

\author{
Guillaume Bouleux
}

University of Lyon, University of Saint Etienne, LASPI, Iut de Roanne, 20 Avenue de Paris, 42334 Roanne Cedex, France, guillaume.bouleux@univ-st-etienne.fr, Tel : +334774481 52, Fax : +33477448921

\begin{abstract}
Diagnosing defects on rotating machines can be reached by several angles. When dealing with asynchronous motor drive, such physical elements rotate that a natural angle for treating the healthiness of the motor can be obtained by the use of spectral analysis tools. It is now stated that electrical or mechanical defects, which appear periodically as well, can be retrieved by analyzing the amplitude of particular frequencies inside an estimated power spectrum. When dealing with broken rotor bars detection it is essential to accurately localize the frequencies related to the slip inside the power spectrum. The diagnosis is thereafter made by indicators given with respect to their power. For actual low level of load operations, the supply frequency generally masks the frequencies which could be exploited for indicators. Therefore, we propose to cancel, as well as possible, the contribution of this supply frequency to develop the useful and closely components. The resolution should be very thin for the components to be estimated. In consequence, we use a prior-knowledge subspace-based frequency estimator, already developed in the literature, we complete with an Oblique Projection coupled with a Total Least Squares solution for estimating the power of the resulting estimated frequencies. Finally, we show by means of a real application how it contributes to improve the power spectrum estimation when compared to the FFT or periodogram-based analysis and how the aforementioned power spectrum makes the diagnosis indicator of rotor bars efficient.
\end{abstract}

Keywords: Induction Machine, fault diagnosis, Motor Current Signal Analysis, frequency estimation, rotor bars

\section{Introduction}

It is a fact, the diagnosis of electrical or mechanical defects of an induction motor has concerned and focused the attention since the last two decades [1-12]. Based on the electrical modeling of the machine $[13,14]$ and on the choice of the sensor-type, several approaches have been proposed [15-19]. Usually, but not only, the major manner of acquiring a significant signal from the motor is made by acoustic [20], vibratory $[21,22]$ or current acquisition $[23,24]$. Each has its advantages and of course its drawbacks; it will depend on the default characterization and eventually the motor drive particularity [21, 25-27]. However, we point out 
that all these technics measure periodic information directly came from the motor. The inherent rotation of bearings, magnetic fields or currents inside the motor, is relevant information that a vibratory, an acoustic or obviously a current signal carry on. Accepting the time periodicity allows us to relate the different faults to a frequency-based examination of the signal acquired. Depending on the severity of the default, the power of the related frequencies will clearly evolve. The diagnosis can in consequence be performed by analyzing an indicator based on the power ratio between the supply frequency and its sidebands components [25, 27]; the more this ratio increases the more faulty the motor is.

The first works on this topic were focused on Power Spectral Density (PSD) or related and closely works essentially based on periodogram-like treatment. The non-parametric estimation procedure gives then estimation of both, frequencies and amplitudes needed for obtaining an efficient diagnostic indicator. These kinds of approaches were certainly first confidence approach giving reliable results. However, for broken rotor bars detection, an excellent accuracy location of the sidebands components is essential [7, 28]. Then, overcoming the resolution insufficiency of periodogram-based approaches which we remind, is limited by the Fourier resolution, i.e. the ratio between the sampling frequency and the numbers of samples; high resolution methods have emerged, e.g. the Fast Orthogonal Search (FOS) algorithm [29, 30], some MUSIC-like method [27, 31-33] or ESRIT-like improvement [34] and Markov-based methods for frequency estimation [35]. The high resolution property of these methods is obtained thanks to an algebraic parameterization of the acquisition signal which permits the use of mathematical concepts of vector subspaces. Two estimation steps are thus required to fulfill the spectral analysis. Let us summarize the steps by the following: (i) the frequencies are obtained when the subspaces, with respect to those parameters, fit the true ones as closely as possible. This notion gives rise to the more general concept of subspace fitting [36] which group together a large number of subspace-based solutions, including Maximum Likelihood (ML) frequency estimation; (ii) a classical ordinary Least Squares (LS) procedure is utilized for obtaining the power of each estimated frequencies.

Owing to its non-invasive or non-intrusive capability [24], stator current acquisition is increasingly put in place. For squirrel-cage rotor induction motors, electrical defects such as rotor bar defects could be seen inside the stator current signal by monitoring the frequencies around the supply frequency $[1,7,28]$. In such an environment, the driven frequency is undisputedly the most powerful frequency inside the stator current spectrum and it may mask the meaningful sidebands frequencies. To tackle this problem, recent work incorporated the knowledge of the driven frequency into subspace methods for improving the estimation of the remaining frequencies and getting rid of the known one $[33,35,36]$. The question of improving the power estimation of the frequencies that have not been eliminated, and only those ones was an open question to which we respond in the present paper.

The paper is organized as follows. We first state the model of observation in section 2, we then recall in the third section the subspace estimation procedure which takes into account the knowledge of some frequencies; 
section 4 presents the Oblique projection coupled to the Total Least Squares (TLS) solution for improving power spectrum estimation and finally we analyze the method through an application in section 5.

\section{Model Specification}

A classical Hilbert transform is first assumed for suppressing negative frequencies and avoiding aliasing effects. We assume therefore that the signal acquired is the superposition of $d$ complex sinusoids corrupted by an acquisition noise. We suppose the temporal acquisition of $N$ samples of the form

$$
z(t)=\sum_{k=1}^{d} \alpha_{k} e^{j\left(\omega_{k}+\phi_{k}\right)}+n(t), \quad t=1, \ldots, N
$$

where $\alpha_{k}$ is a deterministic and constant amplitude, $\omega_{k}$ is the deterministic pulsation (we will mix up the pulsation and the frequency here and after), $\phi_{k}$ is the initial phase at $t=0$ and assumed to be a random variable taking its values uniformly in the range $[0 ; 2 \pi($. We also assume that $n(t)$ is a random circular and zero mean Gaussian variable independent of $\left\{\omega_{k}\right\}_{k=1}^{d}$ with covariance given by

$$
\mathbb{E}\left[n\left(t_{1}\right) n^{\star}\left(t_{2}\right)\right]=\sigma^{2} \delta\left(t_{1}, t_{2}\right),
$$

where $\mathbb{E}[$.$] stands for the mathematical expectation, the superscript . { }^{\star}$ corresponds to the complex conjugate and where $\delta\left(t_{1}, t_{2}\right)=1$ for $t_{1}=t_{2}$ and is equal to zero for any other values. In order to use a subspace approach, whereas only one sensor is used, we define a data vector $y(t)$ viewed as a windowed partition of the whole data set acquired. Then, $y(t)=[z(t) \ldots z(t+m-1)]^{T}$, with $m$ the window length and ${ }^{T}$ the transpose operator. Henceforth, bold is used to specify the vectors and bold capitals is used for matrix distinction. Consequently, we obtain the so-called matrix representation

$$
\boldsymbol{y}(t)=\boldsymbol{A} \boldsymbol{S} \boldsymbol{w}(t)+\boldsymbol{n}(t)
$$

in which

$$
\boldsymbol{A}=\left[\begin{array}{ccc}
1 & \ldots & 1 \\
\vdots & & \vdots \\
e^{j \omega_{1}(m-1)} & \ldots & e^{j \omega_{d}(m-1)}
\end{array}\right], \quad \boldsymbol{S}=\left[\begin{array}{ccc}
\alpha_{1} e^{j\left(\phi_{1}\right)} & & 0 \\
& \ddots & \\
0 & & \alpha_{d} e^{j\left(\phi_{d}\right)}
\end{array}\right],
$$

and where $\boldsymbol{w}(t)=\left[e^{j \omega_{1} t} \ldots e^{j \omega_{d} t}\right]$. The complex vector $\boldsymbol{n}(t)$ is a random circular and zero mean Gaussian vector with covariance $\mathbb{E}\left[\boldsymbol{n}(t) \boldsymbol{n}^{H}(t)\right]=\sigma^{2} \boldsymbol{I}$ where ${ }^{H}$ means conjugate transpose and where $\boldsymbol{I}$ is the identity matrix. The algebraic representation of the linear application between the input complex sinusoids and the $(N-m+1)$ virtual output realization of the stochastic process is reached by staking the $(N-m+1)$ windowed data vectors such as

$$
\boldsymbol{Y}=(\boldsymbol{y}(t) \ldots \boldsymbol{y}(t+N-m+1))
$$


For an initial time $t=0$, we obtain the matrix $\boldsymbol{Y}=[\boldsymbol{y}(0) \ldots \boldsymbol{y}(N-m+1)]$ which is a Hankel matrix whose the basic form is

$$
\boldsymbol{Y}=\left(\begin{array}{cccc}
y(0) & y(1) & \ldots & y(N-m-+1) \\
y(1) & y(2) & & \vdots \\
\vdots & \vdots & & \vdots \\
y(m-1) & y(m) & \ldots & y(N-1)
\end{array}\right)=\boldsymbol{A S} \boldsymbol{W}+\boldsymbol{N}
$$

with $\boldsymbol{W}=[\boldsymbol{w}(0) \ldots \boldsymbol{w}(N-m+1)]$ and $\boldsymbol{N}=[\boldsymbol{n}(0) \ldots \boldsymbol{n}(N-m+1)]$. Then, the output matrix can be built by staking in column-wise the $(N-m+1)$ data windowed samples of the original and available data set. For ease of reading and notation, we have not explicitly written the $\boldsymbol{\omega}$ dependence of $\boldsymbol{A}$. It is however necessary to keep in mind that the frequencies will be estimated thanks to the subspace spanned by the columns of $\boldsymbol{A}$ and that the amplitudes and a posteriori the power of the sinusoids will be estimated thanks to the $\boldsymbol{S}$ matrix. The challenge is thus to estimate both the frequencies $\left\{\omega_{k}\right\}_{k=1}^{d}$ and the amplitudes $\left\{\alpha_{k}\right\}_{k=1}^{d}$ with only the observation matrix $\boldsymbol{Y}$.

In modeling the asynchronous motor drive electrically, we can easily point out the relations between a default on one or several rotor bars and the electromotive force of the machine (cf. references inside [25]). Indeed, the inductive current admits an analytic expression in which clearly the defaults are visible through the apparition of harmonics around the on line frequency or the driven frequency. Basically, we have the well known equality

$$
f_{s b}=(1+2 k g) f_{r}, \quad k \in \mathbb{Z}^{*}
$$

where $g$ is the slip coefficient, $f_{r}$ the driven frequency which could be $50 \mathrm{~Hz}$ or $60 \mathrm{~Hz}$ and $f_{s b}$ the frequency of sidebands components. For monitoring as well as possible and diagnose with a high confidence level, it is sufficient to at least inspect the sidebands components; but this could be made difficult if the frequencies are close to the online one, especially for low level of load operations. In addition, the power of, for example, the $50 \mathrm{~Hz}$, is by far the most important one. These conditions pushed up for treating the problem with a new viewpoint. The interest is no more the estimation of the whole frequency set $\left\{\omega_{k}\right\}_{k=1}^{d}$ but only a subset where the $50 \mathrm{~Hz}$, and possibly its harmonics, would be somehow mathematically filtered but useful for improving the estimation of the other frequencies. The challenge is in consequence to utilize the $50 \mathrm{~Hz}$ (and its harmonics if any) to improve the estimation of a subset $\left\{\omega_{k}\right\}_{k=1}^{d_{u}}$, with $d_{u}$ the number of unknown frequencies, and to estimate thereafter their associated power. The two following sections are dedicated to these tasks.

\section{Estimating the frequencies with support of $50 \mathrm{~Hz}$}

We consider that there already exist solutions to this problem, this section will then draw the principal steps of the method; to have a comprehensive idea, we advise the reader to refer themselves to the works 
$[35,37]$ and the references therein.

\subsection{The method principle}

Let start by introducing the following polynomial

$$
Q(z) \triangleq b_{0} z^{d}+b_{1} z^{d-1}+\ldots+b_{d}=b_{0} \Pi_{k=1}^{d}\left(z-e^{j \omega_{k}}\right)
$$

for which the argument of each zero is the frequency of interest. It is easy to incorporate the knowledge of the $50 \mathrm{~Hz}$ and its harmonics inside this polynomial. It suffices for this to factorize $Q(z)$ by the known zeros associated with the known frequencies. We obtain consequently the following expression

$$
Q(z)=P_{u}(z) P_{k}(z)
$$

where the polynomial $P_{k}(z)$ is composed by the known $d_{k}$ zeros/frequencies and the polynomial $P_{u}(z)$ by the $d_{u}$ unknown zeros/frequencies in the following manner

$$
\begin{aligned}
P_{u}(z) \triangleq \bar{b}_{0} z^{d_{u}}+\bar{b}_{1} z^{d_{u}-1}+\ldots+\bar{b}_{d_{u}} & =\bar{b}_{0} \Pi_{k=1}^{d_{u}}\left(z-e^{j \omega_{k}}\right) \\
P_{k}(z) \triangleq c_{0} z^{d_{k}}+c_{1} z^{d_{k}-1}+\ldots+c_{d_{k}} & =c_{0} \Pi_{k=1}^{d_{k}}\left(z-e^{j \omega_{k}}\right) .
\end{aligned}
$$

The problem of frequency estimation is then reported to the estimation of the unknown polynomial coefficients $\left\{\bar{b}_{k}\right\}_{k=1}^{d_{u}}$.

\subsection{How to reach the frequencies}

Owing to the definition of $Q(z)$, we have the crucial algebraic property

$$
\boldsymbol{B}^{H} \boldsymbol{A}=\mathbf{0}
$$

in which the matrix $\boldsymbol{B}^{H}$ of size $(m-d)$ admits the structure

$$
\boldsymbol{B}^{H}=\left[\begin{array}{cccccc}
b_{d} & \ldots & b_{0} & 0 & \ldots & 0 \\
0 & b_{d} & \ldots & b_{0} & 0 & \vdots \\
\vdots & 0 & \ddots & \ddots & \ddots & 0 \\
0 & \ldots & 0 & b_{d} & \ldots & b_{0}
\end{array}\right]
$$

This relation basically means that the vector $\boldsymbol{b}^{H}=\left[b_{d} \ldots b_{0}\right]$ belongs to the kernel of the $\boldsymbol{A}$ matrix; if we assume that the columns of $\boldsymbol{A}$ span the signal subspace then we will say that $\boldsymbol{b}$ belongs to the noise subspace in reference to the statistical independence and representation and that of noise. The set $\left\{b_{k}\right\}_{k=1}^{d}$ could be consequently estimated when the orthogonality between $\boldsymbol{b}$ and the columns of $\boldsymbol{A}$ is maximal. It is then 
necessary to have access to the signal subspace or an estimate of it.

Let start with the sample covariance matrix defined by

$$
\hat{\boldsymbol{R}}=\frac{1}{N-m+1} \sum_{t=1}^{N-m+1} \boldsymbol{y}(t) \boldsymbol{y}^{H}(t)
$$

and perform next an eigenvalue decomposition of the sample covariance to obtain

$$
\hat{\boldsymbol{R}}=\hat{\boldsymbol{E}}_{s} \hat{\Lambda}_{s} \hat{\boldsymbol{E}}_{s}^{H}+\hat{\boldsymbol{E}}_{n} \hat{\Lambda}_{n} \hat{\boldsymbol{E}}_{n}^{H}
$$

where $\hat{\boldsymbol{E}}_{\boldsymbol{s}}$ is the $(m \times d)$ matrix containing the $d$ eigenvectors associated with the $d$ largest eigenvalues, rearranged in the diagonal matrix $\hat{\boldsymbol{\Lambda}}_{\boldsymbol{s}}$ whereas $\hat{\boldsymbol{E}}_{\boldsymbol{n}}$ is the $(m \times m-d)$ matrix containing the remaining $(m-d)$ eigenvectors associated with the $(m-d)$ remaining eigenvalues, rearranged in the diagonal matrix $\hat{\boldsymbol{\Lambda}}_{n}$. Obviously, the columns of $\hat{\boldsymbol{E}}_{\boldsymbol{s}}$ span a signal subspace estimate.

Define next $\hat{\boldsymbol{e}}_{\boldsymbol{s}_{\boldsymbol{k}}}$ as the $k$-th vector of $\hat{\boldsymbol{E}}_{\boldsymbol{s}}$. A Maximum Likelihood (ML) estimation procedure is performed from the random sequence $\left\{\boldsymbol{B}^{H} \hat{\boldsymbol{e}}_{\boldsymbol{s}_{1}}, \ldots, \boldsymbol{B}^{H} \hat{\boldsymbol{e}}_{\boldsymbol{s}_{d}}\right\}$ and after algebraic manipulations, $\boldsymbol{b}$ is easily obtained by minimizing the quadratic form $\boldsymbol{b}^{H} \boldsymbol{Q} \boldsymbol{b}$ where $\boldsymbol{Q}$ is explicitly given in reference [37] where the reader will find all materials needed for the criterion derivation.

We now use the convolution property

$$
\boldsymbol{b}=\boldsymbol{C} \bar{b}
$$

with

$$
C^{T}=\left[\begin{array}{cccccc}
c_{0} & \ldots & c_{d_{k}} & 0 & \ldots & 0 \\
0 & c_{0} & \ldots & c_{d_{k}} & 0 & \vdots \\
\vdots & 0 & \ddots & \ddots & \ddots & 0 \\
0 & \ldots & 0 & c_{0} & \ldots & c_{d_{k}}
\end{array}\right]
$$

and

$$
\overline{\boldsymbol{b}}=\left[\bar{b}_{0} \ldots \bar{b}_{d_{u}}\right]^{T}
$$

and where $\boldsymbol{C}$ is of size $(d+1) \times\left(d_{u}+1\right)$, to give below, the minimization criterion from which the $\left\{\bar{b}_{k}\right\}_{k=1}^{d_{u}}$ will be estimated

$$
\min _{\bar{b} \text { s.t. }\|b\|^{2}} \bar{b}^{H} \boldsymbol{C}^{T} \boldsymbol{Q} \boldsymbol{C}^{\star} \bar{b}
$$

with .* the conjugate operator. Different hints for solving (18) can be found in [35-37]. Once $\overline{\boldsymbol{b}}$ is obtained, the frequencies are deduced from the roots of $P_{u}(z)$.

We have now to treat the problem of the amplitudes/power for fulfilling a good diagnosis. 


\section{The TLS-based amplitude estimation}

When the frequencies have been estimated the acquisition model (6) is modified to explicitly point out the dependence on the known and unknown frequency contribution and it yields

$$
\boldsymbol{Y}=\underbrace{\left[\boldsymbol{A}\left(\boldsymbol{\omega}_{k}\right) \boldsymbol{A}\left(\hat{\boldsymbol{\omega}}_{u}\right)\right]}_{\hat{\boldsymbol{A}}(\boldsymbol{\omega})} \underbrace{\left[\begin{array}{c}
\boldsymbol{S}_{k} \\
\boldsymbol{S}_{u}
\end{array}\right]}_{\boldsymbol{S}} \underbrace{\left[\begin{array}{ll}
\boldsymbol{W}_{k} & \boldsymbol{W}_{u}
\end{array}\right]}_{\boldsymbol{W}}+\boldsymbol{N}
$$

where the Vandermonde matrix $\hat{\boldsymbol{A}}(\omega)$ has been portioned between the sub-matrix $\boldsymbol{A}\left(\hat{\boldsymbol{\omega}}_{\boldsymbol{u}}\right)$ of estimated unknown frequencies and the sub-matrix $\boldsymbol{A}\left(\boldsymbol{\omega}_{k}\right)$ of known frequencies. Based on (19) we aim at estimating only the unknown amplitudes. For this to be achieved, we have to first cancel off the contribution of known quantities such as the frequencies and the amplitudes from (19) and then only estimate by a Total Least Squares (TLS) approach the remaining amplitudes. This is summed up by

1. Obtaining a model which could be similar to

$$
\boldsymbol{Y}_{r}=\boldsymbol{A}\left(\hat{\boldsymbol{\omega}}_{u}\right) \boldsymbol{S}_{u} \boldsymbol{W}_{u}+\boldsymbol{N}_{r}
$$

2. Estimating the amplitudes $\hat{\boldsymbol{S}}_{u}$ from $(20)$.

This two stage procedure is developed in the next sections.

\subsection{Preprocessing the data observation}

Reducing the number of linear combinations inside (19) is a task which has been of some concern in several works [38]. A possible way to tackle this problem is to basically null the known column-subspace $\boldsymbol{A}\left(\boldsymbol{\omega}_{k}\right)$ while leaving the unknown column-subspace $\boldsymbol{A}\left(\hat{\boldsymbol{\omega}}_{u}\right)$ unaltered. The work of Behrens and Scharf [39], we briefly recall, is a lead for solving this problem.

One can start by examining the orthogonal projection onto the entire signal subspace when it explicitly depends on the known and unknown subspaces. We have then

$$
\begin{aligned}
\boldsymbol{P}_{\left[\boldsymbol{A}\left(\omega_{k}\right) \boldsymbol{A}\left(\hat{\boldsymbol{\omega}}_{u}\right)\right]} & =\left[\boldsymbol{A}\left(\boldsymbol{\omega}_{k}\right) \boldsymbol{A}\left(\hat{\boldsymbol{\omega}}_{u}\right)\right]\left(\left[\begin{array}{l}
\boldsymbol{A}^{H}\left(\boldsymbol{\omega}_{k}\right) \\
\boldsymbol{A}^{H}\left(\hat{\boldsymbol{\omega}}_{u}\right)
\end{array}\right]\left[\begin{array}{ll}
\boldsymbol{A}\left(\boldsymbol{\omega}_{k}\right) & \boldsymbol{A}\left(\hat{\boldsymbol{\omega}}_{u}\right)
\end{array}\right]\right)^{-1}\left[\begin{array}{l}
\boldsymbol{A}^{H}\left(\boldsymbol{\omega}_{k}\right) \\
\boldsymbol{A}^{H}\left(\hat{\boldsymbol{\omega}}_{u}\right)
\end{array}\right] \\
& =\left[\boldsymbol{A}\left(\boldsymbol{\omega}_{k}\right) \boldsymbol{A}\left(\hat{\boldsymbol{\omega}}_{u}\right)\right]\left(\left[\begin{array}{ll}
\boldsymbol{A}^{H}\left(\boldsymbol{\omega}_{k}\right) \boldsymbol{A}\left(\boldsymbol{\omega}_{k}\right) & \boldsymbol{A}^{H}\left(\boldsymbol{\omega}_{k}\right) \boldsymbol{A}\left(\hat{\boldsymbol{\omega}}_{\boldsymbol{u}}\right) \\
\boldsymbol{A}^{H}\left(\hat{\boldsymbol{\omega}}_{\boldsymbol{u}}\right) \boldsymbol{A}\left(\boldsymbol{\omega}_{k}\right) & \boldsymbol{A}^{H}\left(\hat{\boldsymbol{\omega}}_{\boldsymbol{u}}\right) \boldsymbol{A}\left(\hat{\boldsymbol{\omega}}_{\boldsymbol{u}}\right)
\end{array}\right]\right)^{-1}\left[\begin{array}{l}
\boldsymbol{A}^{H}\left(\boldsymbol{\omega}_{k}\right) \\
\boldsymbol{A}^{H}\left(\hat{\boldsymbol{\omega}}_{\boldsymbol{u}}\right)
\end{array}\right]
\end{aligned}
$$

using the inversion matrix lemma, we straightforwardly obtain that

$$
\left(\left[\begin{array}{cc}
\boldsymbol{A}^{H}\left(\boldsymbol{\omega}_{k}\right) \boldsymbol{A}\left(\boldsymbol{\omega}_{k}\right) & \boldsymbol{A}^{H}\left(\boldsymbol{\omega}_{k}\right) \boldsymbol{A}\left(\hat{\boldsymbol{\omega}}_{\boldsymbol{u}}\right) \\
\boldsymbol{A}^{H}\left(\hat{\boldsymbol{\omega}}_{\boldsymbol{u}}\right) \boldsymbol{A}\left(\boldsymbol{\omega}_{k}\right) & \boldsymbol{A}^{H}\left(\hat{\boldsymbol{\omega}}_{\boldsymbol{u}}\right) \boldsymbol{A}\left(\hat{\boldsymbol{\omega}}_{\boldsymbol{u}}\right)
\end{array}\right]\right)^{-1}\left[\begin{array}{c}
\boldsymbol{A}^{H}\left(\boldsymbol{\omega}_{k}\right) \\
\boldsymbol{A}^{H}\left(\hat{\boldsymbol{\omega}}_{\boldsymbol{u}}\right)
\end{array}\right]=\left[\begin{array}{l}
\left(\boldsymbol{A}_{k}^{H} \boldsymbol{P}_{\hat{\boldsymbol{A}}_{u}}^{\perp} \boldsymbol{A}_{k}\right)^{-1} \boldsymbol{A}_{k}^{H} \boldsymbol{P}_{\hat{\boldsymbol{A}}_{u}}^{\perp} \\
\left(\hat{\boldsymbol{A}}_{u}^{H} \boldsymbol{P}_{\hat{\boldsymbol{A}}_{k}}^{\perp} \hat{\boldsymbol{A}}_{u}\right)^{-1} \hat{\boldsymbol{A}}_{u}^{H} \boldsymbol{P}_{\boldsymbol{A}_{k}}^{\perp}
\end{array}\right]
$$


where for ease of notation $\boldsymbol{A}\left(\boldsymbol{\omega}_{k}\right)$ and $\boldsymbol{A}\left(\hat{\boldsymbol{\omega}}_{\boldsymbol{u}}\right)$ have been replaced by $\boldsymbol{A}_{k}$ and $\hat{\boldsymbol{A}}_{u}$ respectively, $\boldsymbol{P}_{\boldsymbol{A}_{k}}^{\perp}$ is the orthogonal projection onto the complementary subspace of $\boldsymbol{A}_{k}$ (i.e. the null space $\boldsymbol{N}\left(\boldsymbol{A}_{k}\right)$ ) basically defined by $\boldsymbol{P}_{\boldsymbol{A}_{k}}^{\perp}=\boldsymbol{I}-\boldsymbol{A}_{k}\left(\boldsymbol{A}_{k}^{H} \boldsymbol{A}_{k}\right)^{-1}$ and similarly $\boldsymbol{P}_{\boldsymbol{A}_{u}}^{\perp}=\hat{\boldsymbol{A}}_{u}\left(\hat{\boldsymbol{A}}_{u}^{H} \hat{\boldsymbol{A}}_{u}\right)^{-1} \hat{\boldsymbol{A}}_{u}^{H}$ is the orthogonal projector onto $\boldsymbol{N}\left(\hat{\boldsymbol{A}}_{u}\right)$. It clearly follows from (22) that the orthogonal projector onto the entire signal subspace decompose itself as

$$
\boldsymbol{P}_{\left[\boldsymbol{A}\left(\boldsymbol{\omega}_{k}\right) \boldsymbol{A}\left(\hat{\boldsymbol{\omega}}_{u}\right)\right]}=\boldsymbol{P}_{\left(\boldsymbol{A}_{k} \mid \hat{\boldsymbol{A}}_{u}\right)}+\boldsymbol{P}_{\left(\hat{\boldsymbol{A}}_{u} \mid \boldsymbol{A}_{k}\right)} .
$$

The projection operators $\boldsymbol{P}_{\left(\boldsymbol{A}_{k} \mid \hat{\boldsymbol{A}}_{u}\right)}$ and $\boldsymbol{P}_{\left(\hat{\boldsymbol{A}}_{u} \mid \boldsymbol{A}_{k}\right)}$ admit the following definitions

$$
\begin{aligned}
& \boldsymbol{P}_{\left(\boldsymbol{A}_{k} \mid \hat{\boldsymbol{A}}_{u}\right)}=\boldsymbol{A}_{k}\left(\boldsymbol{A}_{k}^{H} \boldsymbol{P}_{\hat{\boldsymbol{A}}_{u}}^{\perp} \boldsymbol{A}_{k}\right)^{-1} \boldsymbol{A}_{k}^{H} \boldsymbol{P}_{\hat{\boldsymbol{A}}_{u}}^{\perp} \\
& \boldsymbol{P}_{\left(\hat{\boldsymbol{A}}_{u} \mid \boldsymbol{A}_{k}\right)}=\hat{\boldsymbol{A}}_{u}\left(\hat{\boldsymbol{A}}_{u}^{H} \boldsymbol{P}_{\boldsymbol{A}_{k}}^{\perp} \hat{\boldsymbol{A}}_{u}\right)^{-1} \hat{\boldsymbol{A}}_{u}^{H} \boldsymbol{P}_{\boldsymbol{A}_{k}}^{\perp}
\end{aligned}
$$

and are seen as oblique projectors. Indeed, $\boldsymbol{P}_{\left(\hat{\boldsymbol{A}}_{u} \mid \boldsymbol{A}_{k}\right)}$ projects onto the subspace spanned by the columns of $\hat{\boldsymbol{A}}_{u}$, along with the subspace spanned by the columns of $\boldsymbol{A}_{k}$. The effects of the vectors of $\boldsymbol{A}_{k}$ are therefore annulled while the information contained in the columns of $\hat{\boldsymbol{A}}_{u}$ is unaffected. For more explanations and geometrical interpretations we invite the reader to see [39]. In conclusion, we build the oblique projector $\boldsymbol{P}_{\left(\hat{\boldsymbol{A}}_{u} \mid \boldsymbol{A}_{k}\right)}$ from the estimated frequencies and the known frequencies (50 $\mathrm{Hz}$ and its harmonics for example), and project the data observation matrix $\boldsymbol{Y}$ onto the unknown subspace spanned by the columns of $\hat{\boldsymbol{A}}_{u}$ along with the known subspace. This way, we now have an observation model equivalent to (20). The amplitudes can in consequence be estimated via general linear estimation procedures.

\subsection{The TLS procedure for amplitude estimation}

In this section, we propose to overcome the difficulty of estimating the amplitudes. Our approach differs from general Least Squares (LS) fit to the data observation in a sense that (i) we use the set of $N-m+1$ vectors instead of using directly the $N$ available samples and (ii) we further use a TLS fit.

If we define

$$
\boldsymbol{y}_{r_{0}}=\boldsymbol{P}_{\left(\hat{\boldsymbol{A}}_{u_{0}} \mid \boldsymbol{A}_{k_{0}}\right)} \boldsymbol{y}_{0}=\hat{\boldsymbol{A}}_{u_{0}} \boldsymbol{s}_{u_{0}}+\boldsymbol{n}_{0}
$$

with $\boldsymbol{y}_{0}$ the vector of $\mathrm{N}$ available data observation, $\hat{\boldsymbol{A}}_{u_{0}}$ the Vandermonde matrix $\hat{\boldsymbol{A}}_{u}$ extended to $\mathrm{N}$ rows, $\boldsymbol{s}_{u_{0}}=\left[\alpha_{1} e^{\phi_{1}} \ldots \alpha_{d_{u}} e^{j \phi_{d_{u}}}\right]^{T}$ the vector of complex amplitudes and $\boldsymbol{n}_{0}$ the $N$ samples additive white Gaussian noise vector; the parameter estimation is generally solved by employing a LS procedure for obtaining

$$
\hat{\boldsymbol{s}}_{u_{0}}=\hat{\boldsymbol{A}}_{u_{0}}^{\sharp} \boldsymbol{y}_{r_{0}}
$$

in which.$^{\sharp}$ denotes the Moore-Penrose pseudo-inverse. Finally, the power of the frequencies is deduced by taking the 2-norm of the estimated vector $\hat{\boldsymbol{s}}_{u_{0}}$. We prefer here to use the stochastic notion of model (20) (or originaly (6)) to directly estimate the amplitudes by using the $N-m+1$ stochastic realizations. Our model is consequently (20) and no more (26). In addition, since $\hat{\boldsymbol{A}}_{u}$ has been estimated, we can consider, without 
loss of generality, that the columns of $\hat{\boldsymbol{A}}_{u}$ have some erroneous values; if we admit that the observations $\boldsymbol{Y}_{r}=\boldsymbol{P}_{\left(\hat{\boldsymbol{A}}_{u} \mid \boldsymbol{A}_{k}\right)} \boldsymbol{Y}$ are measured with some uncertainty, which once again is sufficiently realistic, we fall into the multidimensional TLS problem and not the LS one.

The multidimensional TLS problem [40] minimizes at the same time the errors of both $\boldsymbol{Y}_{r}$ and $\hat{\boldsymbol{A}}_{u}$ in establishing the relation

$$
\left[\begin{array}{ll}
\hat{\boldsymbol{A}}_{u} & \boldsymbol{Y}_{r}
\end{array}\right]\left[\begin{array}{c}
\boldsymbol{S}_{u} \boldsymbol{W}_{u} \\
-\boldsymbol{I}
\end{array}\right] \approx \mathbf{0}
$$

where the approx $\approx$ symbol reflects the error on $\boldsymbol{Y}_{r}$ (the white Gaussian noise $\boldsymbol{N}_{r}$ ). This means that $\left[\boldsymbol{S}_{u} \boldsymbol{W}_{u}^{T}-\boldsymbol{I}^{T}\right]^{T}$ belongs to the kernel (or identically the null space) of $\left[\hat{\boldsymbol{A}}_{u} \boldsymbol{Y}_{r}\right]$. We known, by definition, the rank of $\left[\begin{array}{ll}\hat{\boldsymbol{A}}_{u} & \boldsymbol{Y}_{r}\end{array}\right]$ is $d_{u}$ column-wise whereas the dimension of this matrix is $(m \times N-m+1)$. Finding $\left[\boldsymbol{S}_{u} \boldsymbol{W}_{u}^{T}-\boldsymbol{I}^{T}\right]^{T}$ is equivalent therefore to seeking for the best $d_{u}$-rank approximation of $\left[\hat{\boldsymbol{A}}_{u} \boldsymbol{Y}_{r}\right]$. Owing to the Eckart -Young-Mirsky theorem, the best $d_{u^{-}}$rank approximation is obtained by a truncated Singular Value Decomposition (SVD) of the matrix $\left[\hat{\boldsymbol{A}}_{u} \boldsymbol{Y}_{r}\right]$. We have then the decomposition

$$
\left[\begin{array}{ll}
\hat{\boldsymbol{A}}_{u} & \boldsymbol{Y}_{r}
\end{array}\right]=\boldsymbol{U} \boldsymbol{\Sigma}\left[\begin{array}{ll}
\boldsymbol{V}_{11} & \boldsymbol{V}_{12} \\
\boldsymbol{V}_{21} & \boldsymbol{V}_{22}
\end{array}\right]
$$

in which $\left[\boldsymbol{V}_{11}^{T} \boldsymbol{V}_{21}^{T}\right]^{T}$ is of size $\left(m \times d_{u}\right)$ and thus resolves the best $d_{u}$-rank approximation while the remaining $\left(N-m-d_{u+1}\right)$ right eigenvectors, i.e. $\left[\boldsymbol{V}_{12}^{T} \boldsymbol{V}_{22}^{T}\right]^{T}$, resolve the null space of $\left[\hat{\boldsymbol{A}}_{u} \boldsymbol{Y}_{r}\right]$.

The SVD decomposition is not unique and therefore there exists a unitary permutation matrix $\boldsymbol{\Xi}$ such as

$$
\left[\begin{array}{c}
\boldsymbol{S}_{u} \boldsymbol{W}_{u} \\
-\boldsymbol{I}
\end{array}\right]=\left[\begin{array}{c}
\boldsymbol{V}_{12} \\
\boldsymbol{V}_{22}
\end{array}\right] \boldsymbol{\Xi} .
$$

From (30) we have first the relation

$$
\boldsymbol{\Xi}=-\boldsymbol{V}_{22}^{-1}
$$

from which we deduce the TLS amplitudes parameter estimation

$$
\hat{\boldsymbol{S}}_{u} \hat{\boldsymbol{W}}_{u}=-\boldsymbol{V}_{12} \boldsymbol{V}_{22}^{-1} .
$$

We mean in fine over the $(N-m+1)$ realizations of the amplitudes for having the final estimation. The power of each sinusoid is thereafter computed by taking the 2-norm of the corresponding vector.

With the two previous main sections, we have given the tools for estimating the frequencies and their associated power for monitoring and diagnosing rotor bars defects from a noisy stator current measurement. The following section is dedicated to the analysis of the proposed methods in a real life scenario.

\section{Diagnosing rotor bar defects}

This section focuses on the application of the methods proposed on a real asynchronous motor for diagnosing the case of 1 or 2 broken bars on the squirrel-cage rotor by means of a power spectrum analysis. 
We first present the test bench and the experimental conditions and next we analyze the different results given by the application of the method.

\subsection{Test bench and experimental conditions}

An asynchronous motor drive of $4 \mathrm{KW}$ with a squirrel-cage rotor was used for the experiments. The AC machine was coupled with a DC motor with 2 pole pairs and manufactured by the Entreprise Algerienne des Industries Electrotechniques Electro-Industries-AZAZGA company. We have measured three rotor states healthy, 1 and 2 broken bars. Fig.1 illustrates the cases of healthy rotor and 2 broken bars conditions. The purely subjective choice of drilling rotor bars at the junction of one bar and the shorted ring was adopted due to the high failure rate in this position. Indeed, it is more likely that the bars will break at the welding between both elements. Finally, the load varies thanks to resistances connected to the DC drive which in turn becomes a DC generator.

We have used hall effect sensors for measuring voltage and current signals and they have been acquired via an acquisition card IOTEQ/DAQ 1005 series with a sampling frequency $f_{s}=200 \mathrm{KHz}, 16$ analog inputs and 16 digital inputs.
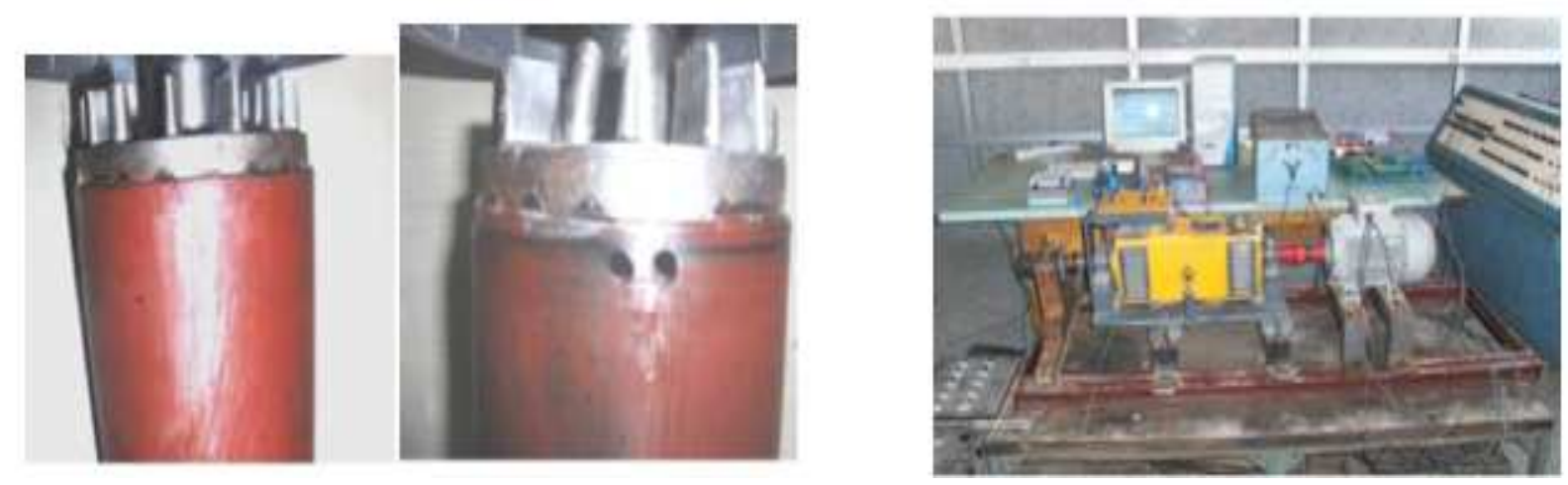

Figure 1: From left to right, healthy rotor and 2 Broken Bars, snapshot of the experimental test Bench

\subsection{Improving the Power Spectrum estimation}

To be in accordance with the complex data model observation (6) we have first and foremost Hilbert transform the stator current signal that was measured. We first show and remind the difficulties of periodogrambased analysis. To illustrate the concept, we use the signal of a healthy machine under nominal level of load and only 10s of acquisition with sampling frequency equal to $10 \mathrm{KHz}$. We invite the reader to refer to Fig.2 for visual results. As we could expect, the $50 \mathrm{~Hz}$ driven frequency is by far the most powerful component inside the spectrum with about $30 \mathrm{~dB}$. From Fig.2-(a) we can clearly see some of the harmonics of the supply frequency, say $100 \mathrm{~Hz}$ and $150 \mathrm{~Hz}$ with odd harmonics prominent; we also see approximate 
frequencies of $25,67 \mathrm{~Hz}$ and $74,43 \mathrm{~Hz}$. These 2 frequencies are extremely relevant since they correspond to the $50 \mathrm{~Hz}$ amplitude modulated by the rotation motion. The slip can be estimated by the side components 52,53 and 47,55 Hz given by Fig.3-(b), which illustrates the proposed method when we have lows-pass filtered the signal and downsampled it by a factor of 10. Owing to the relation $(1+2 g) f_{r}=f_{s b}$ we can find approximately $g=0,025$ and next deduce the rotation speed of the rotor by $25-25^{*} 0.025=24,37 \mathrm{~Hz}$. Then, the 2 frequencies figured out here are 25,62 and $74,37 \mathrm{~Hz}(50-24,37$ and $50+24,37)$. Let us pause and note that the interpretation of these frequencies is only made possible by the use of Fig.3-(b), which clearly gives evidence to the sidebands components. Neither Fig.2-(a) nor Fig.2-(b) have sufficiently discriminated the frequencies to have the information of the sidebands; even if Fig.2-(b) uses the Welch optimal estimator. Actually, accuracy is reached but resolution is a bit lost with this method.

We then wanted to have an idea whether a refined FFT-algorithm, such as the ZOOMFFT technique (see the references of [7]) could improve the estimation of the sidebands. The principle is to low-pass filter the 10s of the healthy machine at nominal level of load with a cut of frequency of $100 \mathrm{~Hz}$ (Fig.3-(a)) and next downsample it by a factor of 10 . We observe that once again, this procedure is unable to estimate the sidebands components around the driven frequency, Fig.4 draws that fact.

In short, we have shown that for 10s of acquisition, low-pass filtered and downsampled by a factor of 10 , leading to a new sampling frequency equal to $1 \mathrm{KHz}$; the proposed method which integrates the $50 \mathrm{~Hz}$ and for which an oblique pre-processing followed by a TLS solution is employed was clearly better than classical PSD or FFT-based analysis for spectrum estimation. This fundamental observation, developed for the case of a healthy machine at nominal level of load is furthermore reinforced by the results depicted in Fig.5 and Fig.6 for which the machine has 1 broken bar at respectively nominal and low level of load. Finally, with no ambiguity, whatever the load and the number of broken bars, Fig. 5 to Fig. 8 , the proposed method undisputedly gives the frequencies related to the sidebands. This estimation will next help us when it comes to using a diagnosis indicator.

\subsection{A diagnosis though improved}

In this part, we exploit the frequencies related to the sidebands components for they help to have an indicator of the rotor bars state. We use so the concept of power ratio between the supply frequency and the sidebands components [25], with for example [27]

$$
\mathcal{I}=\sum_{k \in \mathcal{S}}\left(\frac{s_{k}^{2}}{s_{0}^{2}}\right)
$$

where $\mathcal{S}=\left\{k \in \mathbb{Z}^{*} \mid f_{s b}=(1+2 k g) f_{r}\right.$ is estimated $\}$. We have used this indicator in conjunction with the high resolution method proposed in [27] for the same conditions as for the experience of Fig.3-(b), 5 and 7. The results are reported inside table1. 


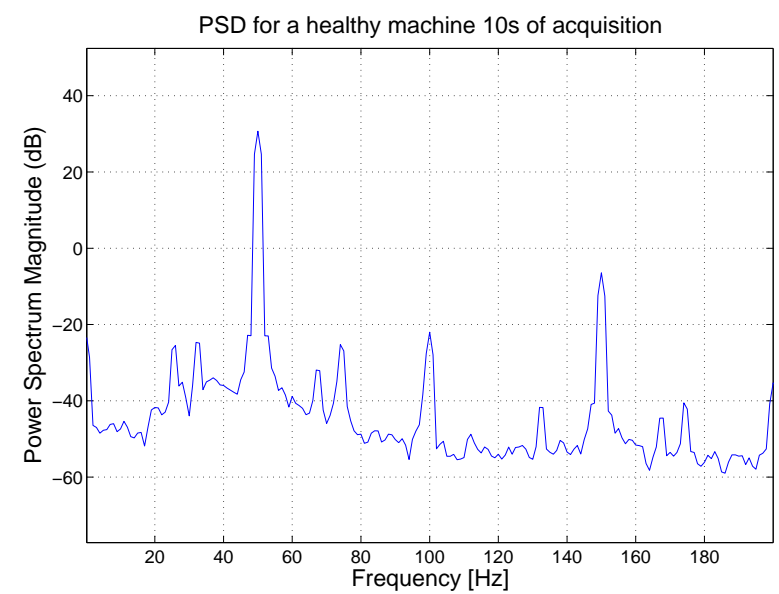

(a)

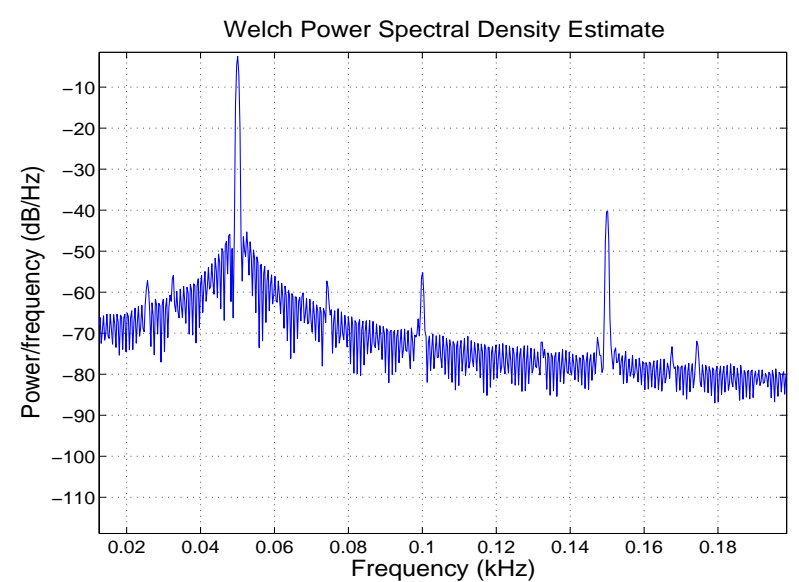

(b)

Figure 2: 10s of acquisition for a healthy machine, (a) PSD, (b) Welch Estimator with optimal overlapping windows
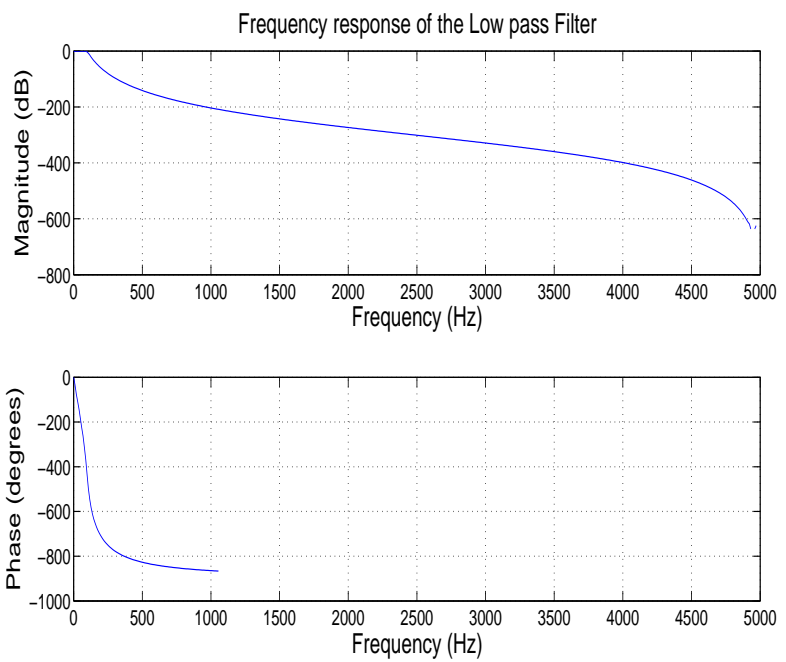

(a)

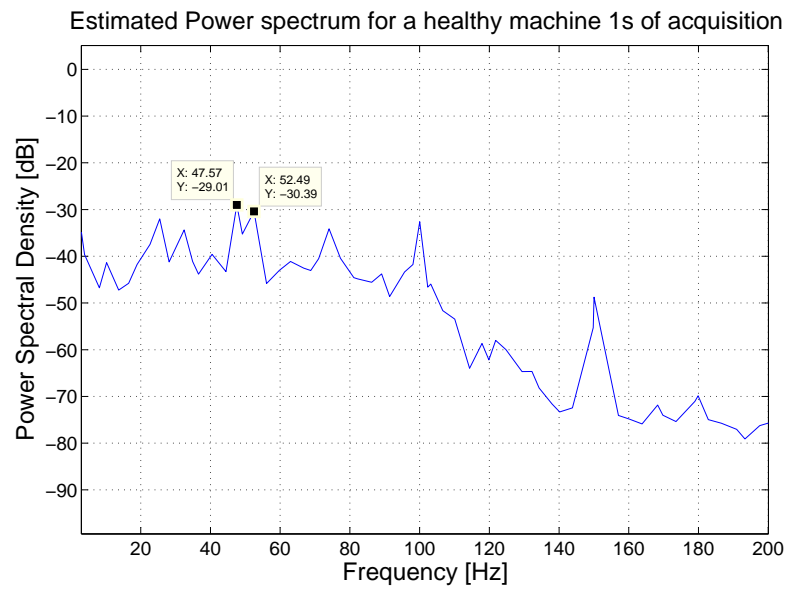

(b)

Figure 3: (a) Low-pass frequency response, cut off frequency $100 \mathrm{~Hz}$, (b) 1 s of acquisition, current signal Low pass Filtered and downsampled by a factor of 10 for nominal level of load, healthy machine, Estimated Power Spectrum by the proposed method.

\begin{tabular}{|l||c|c|c|c|}
\hline State & $f_{r}(\mathrm{~Hz})$ & $k$ & $2 g f_{r}(\mathrm{~Hz})$ & $\mathcal{I}\left(\times 10^{-4}\right)$ \\
\hline Healthy & 49.98 & \pm 1 & 0.6 & 3.12 \\
\hline 1 Broken Bar & 50.31 & \pm 1 & 1.2 & 796 \\
\hline 2 Broken Bars & 49.82 & $\pm\{1,2,3\}$ & 1.4 & 4147 \\
\hline
\end{tabular}

Table 1: 


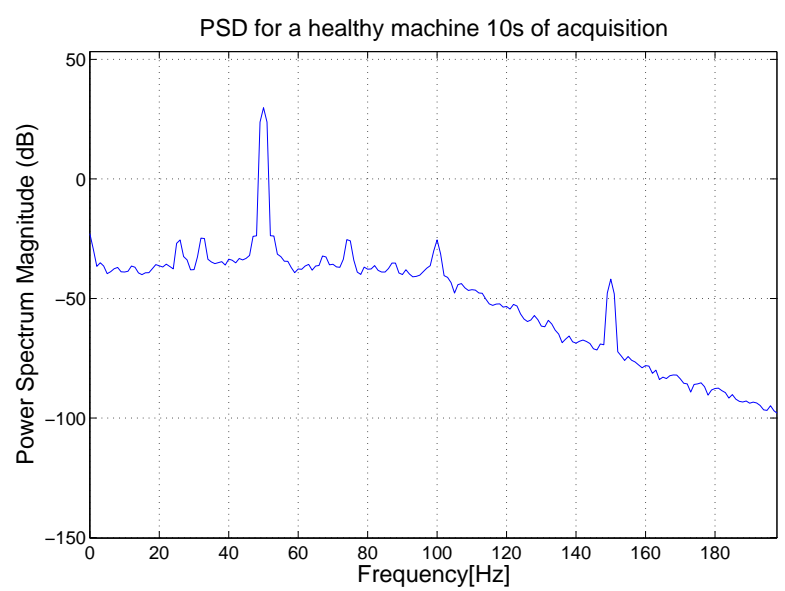

(a)

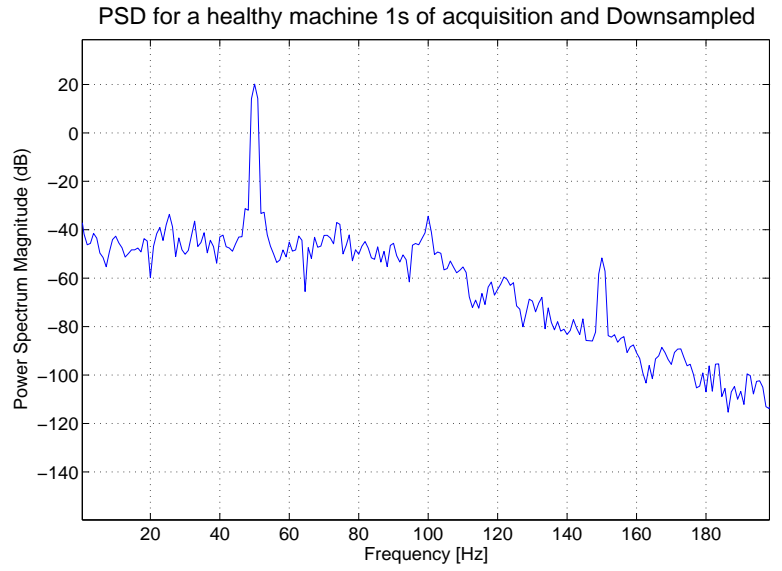

(b)

Figure 4: PSD of current signal Low pass Filtered for a healthy machine, (a) without downsampling, (b) with downsampling equivalent to a ZOOMFFT method.

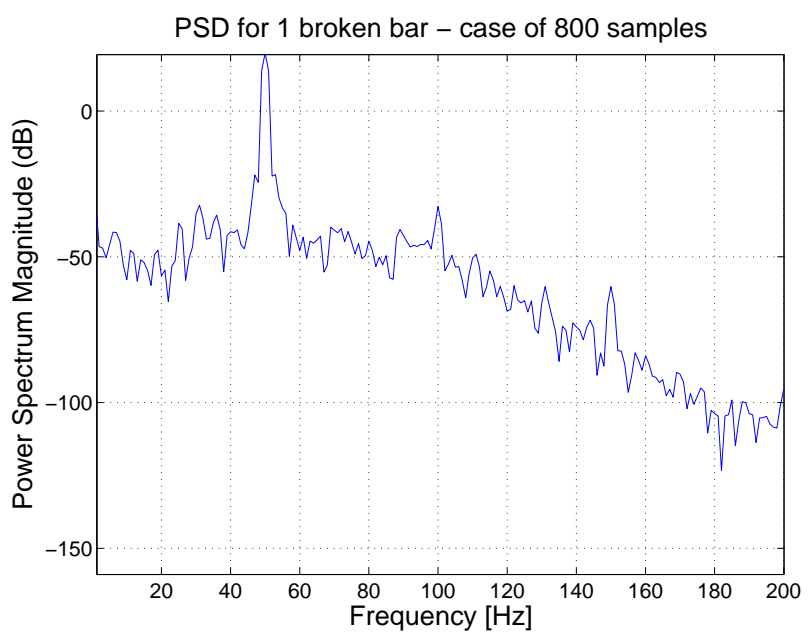

(a)

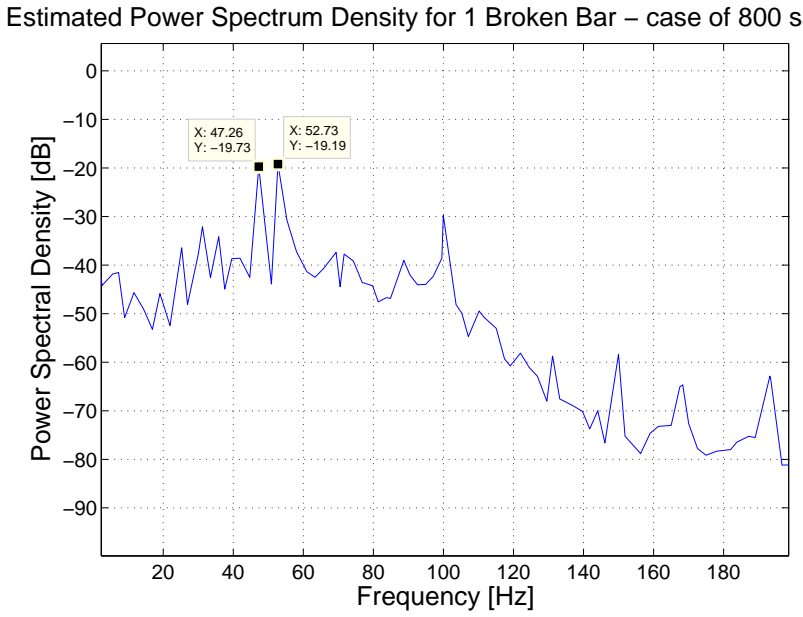

(b)

Figure 5: 800ms of acquisition, current signal Low pass Filtered and downsampled by a factor of 10 for nominal level of load, 1 broken Bar, (a) PSD (b) Estimated Power Spectrum by the proposed method. 


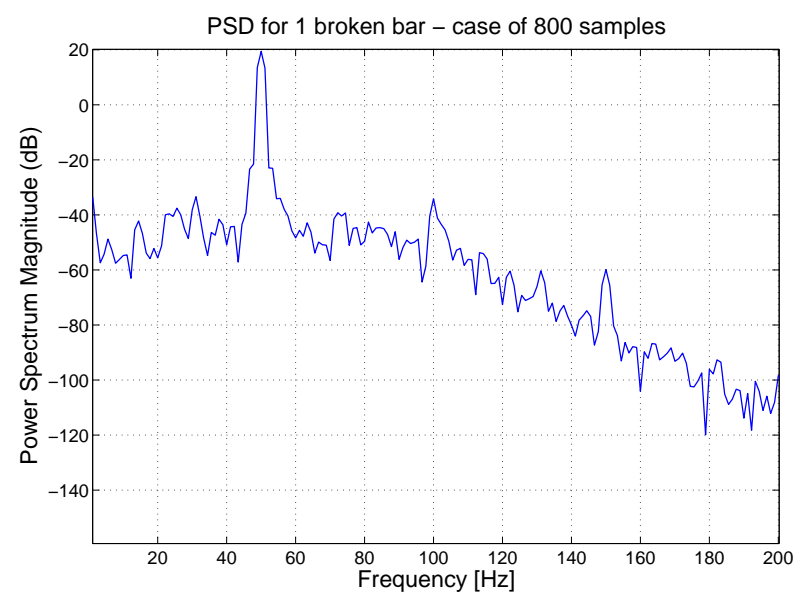

(a)

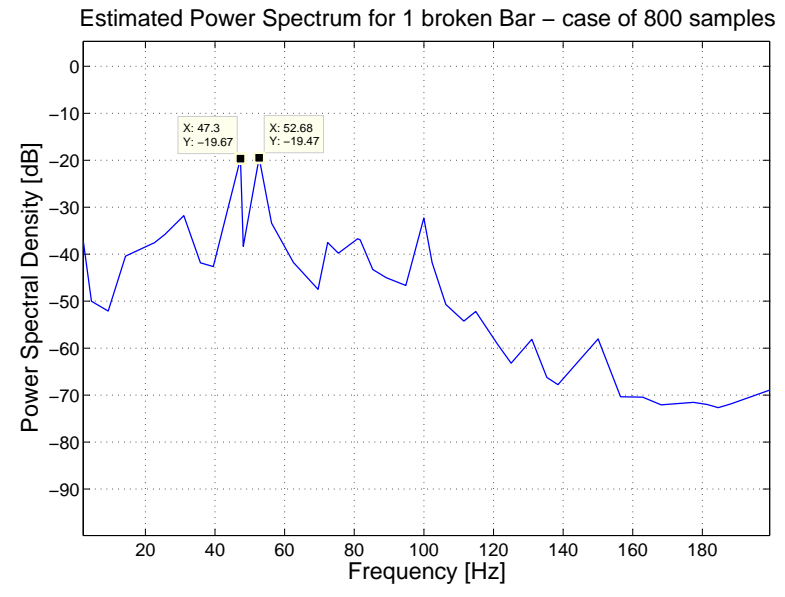

(b)

Figure 6: 800ms of acquisition, current signal Low pass Filtered and downsampled by a factor of 10 for low level of load, 1 broken Bar, (a) PSD (b) Estimated Power Spectrum by the proposed method.

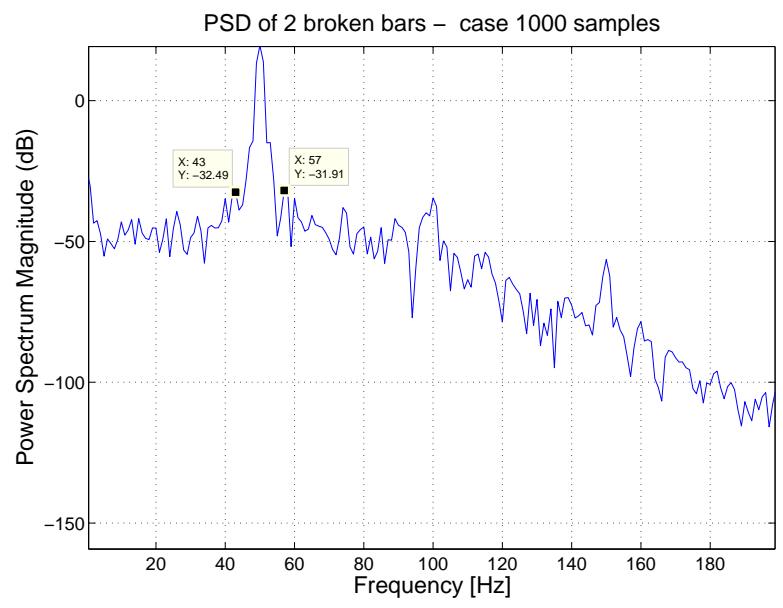

(a)

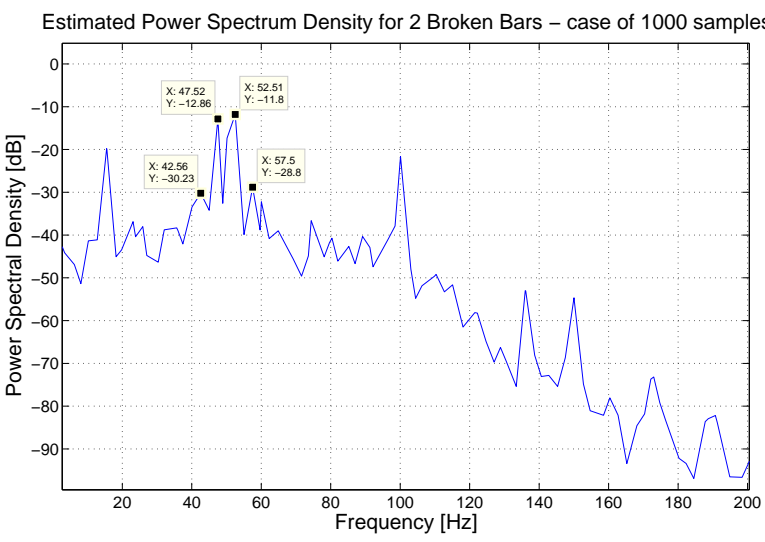

(b)

Figure 7: 1s of acquisition, current signal Low pass Filtered and downsampled by a factor of 10 for nominal level of load, 2 broken Bars, (a) PSD (b) Estimated Power Spectrum by the proposed method. 


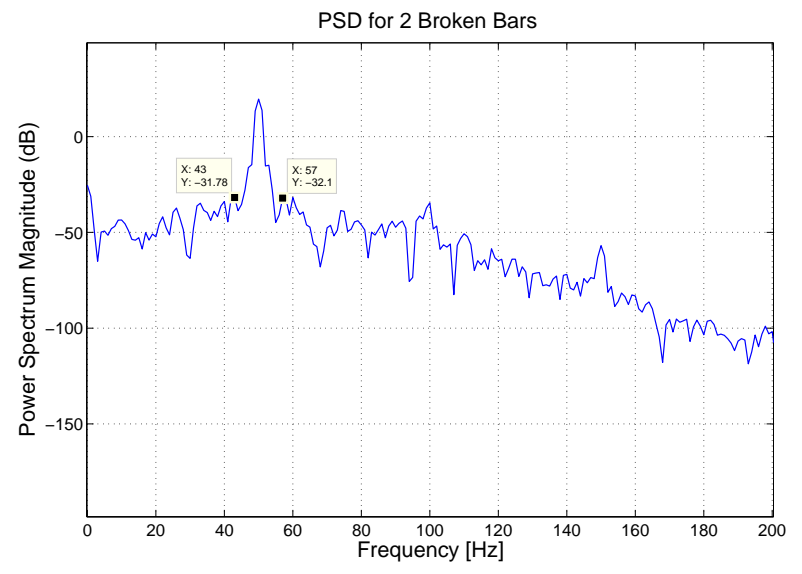

(a)

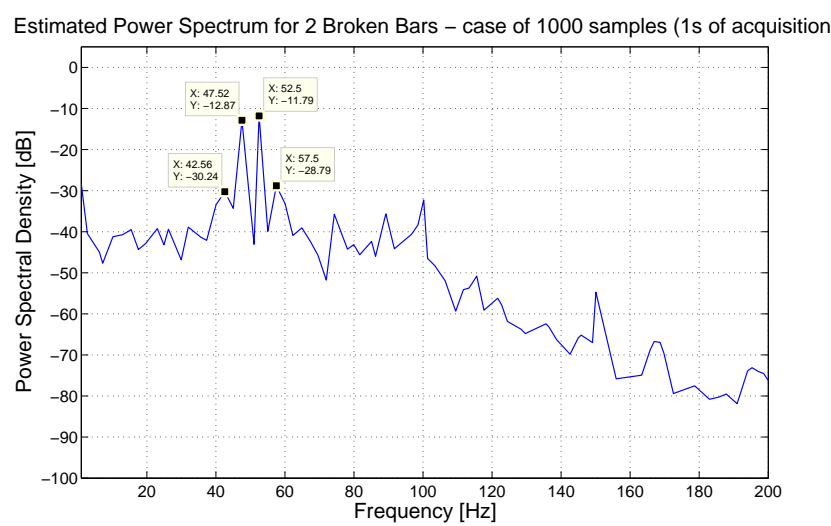

(b)

Figure 8: 1s of acquisition, current signal Low pass Filtered and downsampled by a factor of 10 for low level of load, 2 broken Bars, (a) PSD (b) Estimated Power Spectrum by the proposed method.

\begin{tabular}{|l||c|c|cc|c|}
\hline \multirow{2}{*}{ State } & \multirow{2}{*}{$f_{r}(\mathrm{~Hz})$} & $k$ & \multicolumn{2}{|c|}{$|2 k g| f_{r}(\mathrm{~Hz})$} & $\mathcal{I}\left(\times 10^{-6}\right)$ \\
\hline Healthy & 49.99 & \pm 1 & 2.45 & 2.53 & 7.23 \\
\hline 1 Broken Bar & 50 & \pm 1 & 2.74 & 2.75 & 230 \\
\hline \multirow{2}{*}{ 2 Broken Bars } & 50.02 & $\pm\{1,2\}$ & $\begin{array}{c}2.48 \\
\text { (left) }\end{array}$ & 2.51 & 908 \\
\hline
\end{tabular}

Table 2:

If we only inspect the indicator values of table 1, we find no ambiguity between healthy and damaged rotor bars state. Clearly, we have a ratio between healthy and 1 broken bar condition, approaching the value of 200 and a ratio between 1 and 2 broken bars around 6 . However, the indicator is based on wrong estimated frequencies. The supply frequency is not accurately estimated by the method for at least broken bars scenario and sidebands components are in total error as well, even if their number could be reasonably coherent. In fact, the method of [27] is very sensitive to noisy conditions and the fact the frequencies are estimated by a fixed structure gives a chance to estimate almost everything, leaving a room for artifacts. In conclusion what is the importance/confidence we can give to an indicator built from wrong information. The diagnosis is in consequence questioned and the decision finally becomes hard to make.

Based on the estimated power spectrum of the method proposed in this paper (Fig.5 to Fig.8), we have reported the indicator values inside respectively table 2 and table 3 , for nominal level of load and low level of load. We did not dispose however of the healthy signal acquisition for the low level of load scenario which explains why the indicator is absent in table 3 . 


\begin{tabular}{|l||c|c|cc|c|}
\hline \multirow{2}{*}{ State } & \multirow{2}{*}{$f_{r}(\mathrm{~Hz})$} & $k$ & \multicolumn{2}{|c|}{$|2 k g| f_{r}(\mathrm{~Hz})$} & $\mathcal{I}\left(\times 10^{-6}\right)$ \\
\hline 1 Broken Bar & 50 & \pm 1 & 2.68 & 2.7 & 245 \\
\hline \multirow{2}{*}{ 2 Broken Bars } & 50.01 & $\pm\{1,2\}$ & 2.48 & 2.5 & 1500 \\
\hline
\end{tabular}

Table 3:

Whatever the load conditions, thanks to a better estimated power spectrum, the sidebands components are better estimated and the diagnosis indicator is more significant. From the results of tables 2 and table 3 , we easily see the difference between healthy and failure conditions. The ratio between a healthy and damaged condition is around 30, which leaves no doubt about the decision to make. Similarly, the difference between 1 and 2 broken bars is significant. We have first the number of harmonics growing from 1 to 2 with odd harmonics accurately estimated and next inevitably the increase of the indicator value. The ratio between 1 and 2 broken bars of the latter is for example in between 4 and 7 with the highest difference for the low level of load.

\section{Conclusion}

One of the ways to come to a reliable diagnosis on a machine from current acquisition is to inspect an indicator based on the ratio between the supply frequency and its sidebands components. For different actual operations, the load strongly impacts on the proximity of the sidebands to the driven frequency. The challenge is therefore to be able to estimate these sidebands and especially for low level of load. Classical approaches based on periodogram or FFT-based analysis have shown their inadequacy for such a difficult problem. The idea developed in this paper is then to overcome this difficulty by using a high resolution method designed with the support of the supply frequency. The purpose is therefore to suppress this particular and harmful frequency in the set of frequencies of interest. This method has already been introduced and it gives accurate frequency estimation with a sufficient resolution, allowing to precisely discriminate frequencies such as sidebands. The major point is that the driven frequency no longer exists. The next treatment consists in estimating the power associated with the remaining frequencies. In this paper, we propose to first pre-process the data observation by obliquely projecting it onto a subspace which would be associated with the spectrum of interest, i.e. without the supply frequency, along the subspace in which the supply frequency would live. This consequently accounts for the supply frequency in the data observation and then cancels (almost) its influence on the power spectrum. Once this pre-processing of the data observation has been done, we propose a Total Least Squares (TLS) estimation procedure to finally have the power of each frequency without the impact of the very powerful supply frequency. We have tested this pro- 
cedure in different conditions of load, nominal or low level, for healthy, 1 broken and 2 broken bars against classical FFT analysis, ZOOMFFT method and MUSIC-like criterion especially designed for mechanical defects diagnosing. The results observed for short acquisition duration have clearly shown the limits of these methods. Conversely, the diagnosis given by an indicator based on the power spectrum estimated by the present approach is sure and robust to the load conditions and number of broken bars; even for challenging scenarios.

\section{References}

[1] M. Benbouzid, A Review of Induction Motors Signature Analysis as a Medium for Faults Detection, IEEE Trans. on Industrial electronics 47 (5) (2000) 984-994.

[2] J. Jung, J. Lee, B. Kwon, Online diagnosis of induction motors using MCSA, IEEE Trans. on Industrial Electronics 53 (6) (2006) 1842-1852.

[3] A. Menacer, S. Moreau, G. Champenois, M. Said, A. Benakcha, Experimental Detextion of Rotor Failures of Induction Machines by Stator Current Spectrum Analysis in Function of the Broken rotor Bars Position and the Load, The International Conference on Computer as a Tool (2007) 1752-1758.

[4] Z. Peng, F. Chu, Application of the wavelet transform in machine condition monitoring and fault diagnostics: a review with bibliography, Mechanical Systems and Signal Processing 18 (2) (2004) 199 - 221.

[5] A. K. S. Jardine, D. Lin, D. Banjevic, A review on machinery diagnostics and prognostics implementing condition-based maintenance, Mechanical Systems and Signal Processing 20 (7) (2006) 1483 - 1510.

[6] P. Jayaswal, A. K. Wadhwani, K. B. Mulchandani, Review Article Machine Fault Signature Analysis, International Journal of Rotating Machinery.

[7] M. Mehrjou, N. Mariun, M. Marhaban, N. Misron, Rotor fault condition monitoring techniques for squirrel-cage induction machine - a review, Mechanical Systems and Signal Processing 25 (8) (2011) 2827 - 2848.

[8] L. A. García-Escudero, O. Duque-Perez, D. Morinigo-Sotelo, M. Perez-Alonso, Robust condition monitoring for early detection of broken rotor bars in induction motors, Expert Systems with Applications 38 (3) (2011) 2653 - 2660.

[9] V. T. Tran, B.-S. Yang, An intelligent condition-based maintenance platform for rotating machinery, Expert Systems with Applications 39 (3) (2012) 2977-2988.

[10] G. Didier, E. Ternisien, O. Caspary, H. Razik, A new approach to detect broken rotor bars in induction machines by current spectrum analysis, Mechanical Systems and Signal Processing 21 (2) (2007) 1127 - 1142.

[11] P. Zhang, S. Ding, G. Wang, D. Zhou, A frequency domain approach to fault detection in sampled-data systems, Automatica 39 (7) (2003) $1303-1307$.

[12] G. Dalpiaz, A. Rivola, Condition monitoring and diagnostics in automatic machines: Comparison of vibration analysis techniques, Mechanical Systems and Signal Processing 11 (1) (1997) 53 - 73.

[13] H. R. A. Abed, L. Baghli, A. Rezzoug, Modelling Induction Motors for Diagnostic Purposes, European Conference on power Electronics and Applications (1999) 1-8.

[14] R. Casimir, E. Bouteleux, H. Yahoui, G. Clerc, H. Henao, C. Delmotte, G.-A. Capolino, G. Rostaing, J.-P. Rognon, E. Foulon, L. Loron, H. Razik, G. Didier, G. Houdouin, G. Barakat, B. Dakyo, S. Bachir, S. Tnani, G. Champenois, J.-C. Trigeassou, V. Devanneaux, B. Dagues, J. Faucher, Comparison of modelling methods and of diagnostic of asynchronous motor in case of defects, in: 9th IEEE International Power Electronics Congress, 2004, pp. $101-108$.

[15] C. Cristalli, N. Paone, R. Rodríguez, Mechanical fault detection of electric motors by laser vibrometer and accelerometer measurements, Mechanical Systems and Signal Processing 20 (6) (2006) 1350 - 1361. 
[16] A. Siddique, G. Yadava, B. Singh, A review of stator fault monitoring techniques of induction motors, IEEE Transactions on Energy Conversion 20 (1) (2005) $106-114$.

[17] K. Worden, W. J. Staszewski, J. J. Hensman, Natural computing for mechanical systems research: A tutorial overview, Mechanical Systems and Signal Processing 25 (1) (2011) 4-111.

[18] A. Widodo, B.-S. Yang, Support vector machine in machine condition monitoring and fault diagnosis, Mechanical Systems and Signal Processing 21 (6) (2007) $2560-2574$.

[19] Y.Lei, J. Lin, Z. He, M. J. Zuo, A review on empirical mode decomposition in fault diagnosis of rotating machinery, Mechanical Systems and Signal Processing 35 (1-2) (2013) 108 - 126.

[20] N. Hamzaoui, C. Boisson, C. Lesueur, Vibro-acoustic analysis and identification of defects in rotating machinery, part i: Theoretical model, Journal of Sound and Vibration 216 (4) (1998) 553 - 570.

[21] R. Randall, Vibration-based Condition Monitoring: Industrial, Aerospace and Automotive Applications, Wiley online library, Wiley, 2011.

[22] G. Didier, E. Ternisien, O. Caspary, H. Razik, Fault detection of broken rotor bars in induction motor using a global fault index, IEEE Transactions on Industry Applications 42 (1) (2006) 79-88.

[23] M. Eltabach, J. Antoni, G. Shanina, S. Sieg-Zieba, X. Carniel, Broken rotor bars detection by a new non-invasive diagnostic procedure, Mechanical Systems and Signal Processing 23 (2009) 1398 - 1412.

[24] M. Eltabach, J. Antoni, M. Najjar, Quantitative analysis of noninvasive diagnostic procedures for induction motor drives, Mechanical Systems and Signal Processing 21 (7) (2007) 2838 - 2856.

[25] A. Bellini, F. Filippetti, C. Tassoni, G.-A. Capolino, Advances in Diagnostic Techniques for Induction Machines, IEEE Transactions on Industrial Electronics 55 (12) (2008) 4109-4126.

[26] A. da Silva, Induction motor fault diagnostic and monitoring methods, Ph.D. thesis, Marquette University, Milwaukee, Wisconsin (May 2006).

[27] E. ElBouchikhi, V. Choqueuse, M. Benbouzid, J. Charpentier, Induction machine fault detection enhancement using a stator current high resolution spectrum, in: 38th Annual Conference on IEEE Industrial Electronics Society (IECON), 2012, pp. 3913-3918.

[28] G. King, M. Tarbouchi, D. McGaughey, Current signature analysis of induction machine rotor faults using the fast orthogonal search algorithm, in: 5th IET International Conference on Power Electronics, Machines and Drives (PEMD 2010), IEE, 2010, p. 215.

[29] D. R. McGaughey, M. Tarbouchi, K. Nutt, A. Chikhani, Speed sensorless estimation of ac induction motors using the fast orthogonal search algorithm, IEEE Transactions on Energy Conversion 21 (1) (2006) 112-120.

[30] K. H. Chon, Accurate identification of periodic oscillations buried in white or colored noise using fast orthogonal search, IEEE Transactions on Biomedical Engineering 48 (6) (2001) 622-629.

[31] A. Bracale, G. Carpinelli, L. Piegari, P. Tricoli, A High Resolution Method for On Line Diagnosis of Induction Motors Faults, IEEE Power Tech 2007 (2007) 994-998.

[32] S. Kia, H. Henao, G.-A. Capolino, A High-resolution frequency estimation method for three-phase induction machine fault detection, IEEE Trans. on Industrial Electronics 54 (4) (2007) 2305-2314.

[33] G. Bouleux, A. Ibrahim, F. Guillet, R. Boyer, A subspace-based rejection method for detecting bearing fault in asynchronous motor, in: International Conference on Condition Monitoring and Diagnosis (CMD), 2008, pp. 171-174.

[34] G. Bouleux, T. Kidar, F. Guillet, An improper random vector approach for esprit and unitary esprit frequency estimation, in: 7th International Workshop on Systems Signal Processing and their Applications (WOSSPA), 2011, pp. 299-302.

[35] P. Wirfalt, G. Bouleux, M. Jansson, P. Stoica, Subspace-based frequency estimation utilizing prior information, in: IEEE Statistical Signal Processing Workshop (SSP), 2011, pp. 533-536.

[36] M. Kristensson, M. Jansson, B. Ottersten, Further results and insights on subspace based sinusoidal frequency estimation, 
IEEE Trans. on Signal Processing 49 (12) (2001) 2962-2974.

[37] G. Bouleux, P. Stoica, R. Boyer, An Optimal Prior knowledge-based DOA Estimation Method, in: 17th European Signal Processing Conference, 2009.

[38] H. Chen, S. V. Huffel, D. V. Ormondt, R. de Beer, Parameter Estimation with Prior Knowledge of Known Signal Poles for the Quantification of NMR Spectroscopy Data in the Time Domain, Journal of Magnetic Resonance 119 (2) (1996) $225-234$.

[39] R. Behrens, L. Scharf, Signal Processing Applications of Oblique Projection Operators, IEEE Trans. on Signal Processing 42 (6) (1994) 1413-1424.

[40] S. V. Huffel, J. Vanderwalle, The total least squares problem : computational aspects and analysis, SIAM Publications, 1991. 